\title{
[Artigo Retratado] Acerca da ocorrência de gastrópodes exóticos europeios em terras altas do Estado de Santa Catarina, Região Central Sul do Brasil
}

\section{A. Ignacio Agudo-Padrón}

Projeto “Avulsos Malacológicos - AM," Caixa Postal (P. O. Box) 010. Centro. Florianópolis-SC (CEP 88010-970). E-mail: ignacioagudo@gmail.com; http://noticiasmalacologicas-am.webnode.pt.

Resumo. A presença de duas espécies de lesmas exóticas europeias Ambigolimax valentianus (Férussac, 1822) e Limax maximus (Linnaeus, 1758) (Gastropoda: Limacidae), é verificada, desde o ano de 2011, no Município de Monte Carlo, localizado no Planalto Serrano de Santa Catarina, Região Central Sul do Brasil, acrescentando sua distribuição geográfica previamente conhecida Py Mlicado: 31/12/2015 neste estado, assim como seu problemático avanço invasor território de interesse agrícola.

Receb do: 09/12/2015

Ac) to: $26 / 12 / 2015$ Palavras-chave: Lesmas exóticas europeias, Terras Alts, Santa Catarina, Região Central Sul do Brasil.

Abstract. About the occurrence of European atic gastropods in the highlands of the State of Santa C in entral Southern Brazil. The presence of two species o ip -dyced European slugs Ambigolimax valentianus (Férussac, 18 v) and Limax maximus (Linnaeus, 1758) (Gastropoda: Lim ${ }^{-1}$ ae), is verified since the year 2011 in the Monte Carlo Munic ali y, located in the Highland Plateau Region of Santa Catari a te State, Central Southern Brasil, adding to the previous known Retratado: 15/01/2016 molluscs in this state as as their problematic invasive breakthrough in this are of of ficultural interest.

Keywords: Fxot V: poan slugs, Highland, Santa Catarina State, Central Sout, rn E azil Region.

O pequeno Município de "Monte Carlo" encontra-se localizado uma altitude de 942 m acima do nível do mar na região dos Campos de Altitude, Planalto Serrano do Estado de Santa Catarina-SC (Figura 1), apresentando clima mesotérmico úmido com verão fresco e temperatura média de $16,1^{\circ} \mathrm{C}$. Espacialmente encontra-se enquadrado na Bacia Hidrográfica do Rio Taquaruçu, que por sua vez faz parte da rede que configura a importante Macrobacia do Rio Uruguai.

Dito espaço e natureza hoje sofrem ante o maciço e severo processo de desma- tamento, visivelmente acentuado devido à exploração madeireira, prática intensiva de fruticulturas (maçã principalmente), monocultura de grãos e hortaliças (destaques para trigo, soja, milho, cebola, alho e feijão), pecuária extensiva (gado vacuno, caprino e ovino) e constante aplicação indiscriminada de agrotóxicos, restando apenas nas propriedades rurais aquelas pequenas áreas/ manchas esparsas, porém obrigatórias, de preservação florestal conhecidas como reserva legal, infelizmente pouco representativas na prática do que em outro 


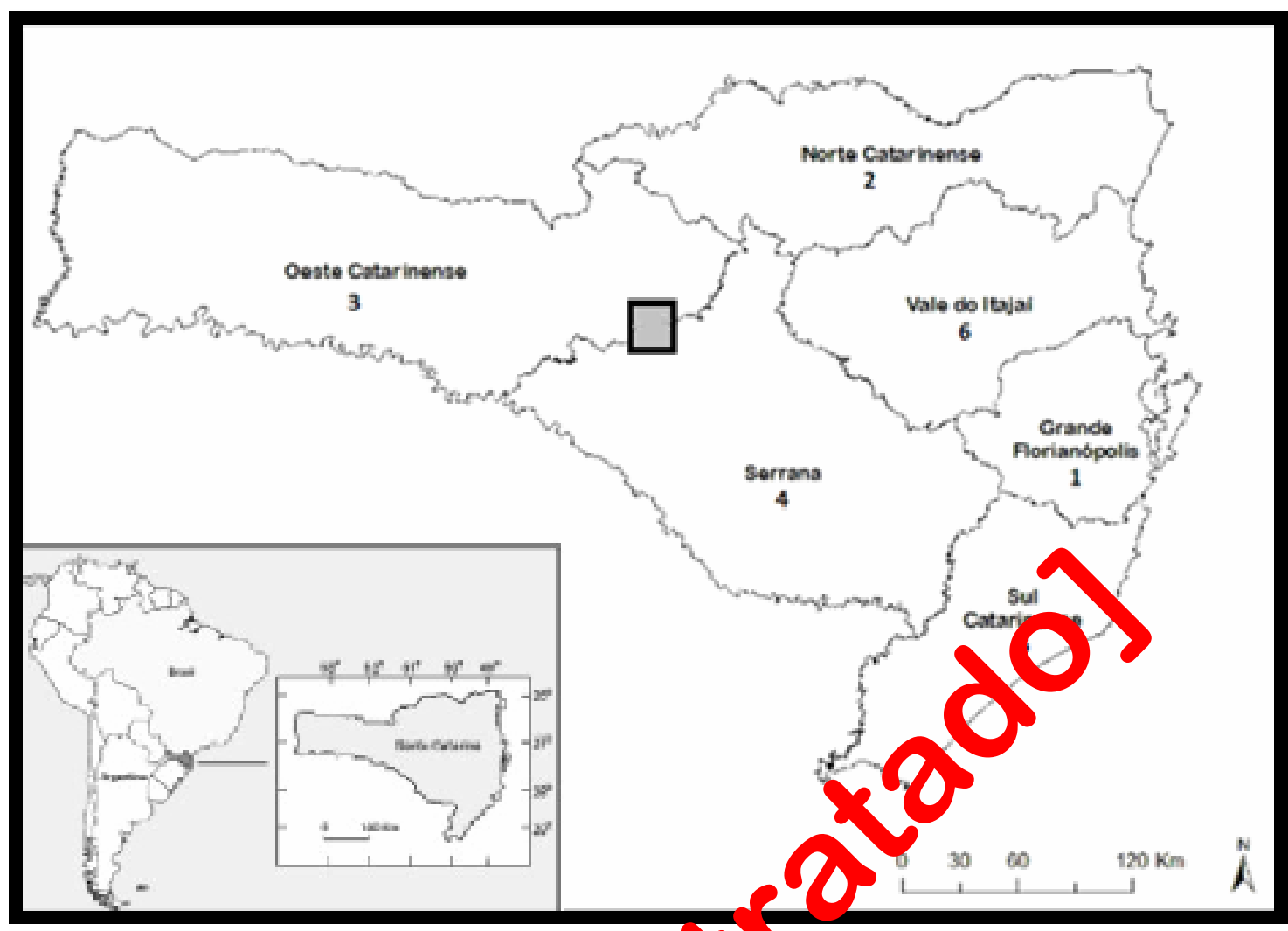

Figura 1. Localização do Município de Monte Carlo (requ dro cinza) no contexto espaço-geográfico dos Campos de Altitude (Região 4 - Serrana) do Planalto C? arinense.

tempo constituiu a grande Flaresta Ombrófila Mista ou Mata de Arau áric do planalto serrano.

Essa crítica situaçăo, rer x pela agressão ambiental pr uto de avanço galopante da interven ao rópica (colonização cabocla, ruincı Imente, com fortes traços de interv tc - migrante Italiana), encontra-se nític mente refletida em detrimento da biodiversidade faunística local, em particular da malacofauna terrícola, sendo que espécies florestais nativas endêmicas de gastrópodes tais como os caracóis Megalobulimus musculus (Bequaert, 1948) (Megalobulimidae), Strophocheilus pudicus (Müller, 1774) (Strophocheilidae), assim como as lesmaslixa Phyllocaulis soleiformis (d'Orbigny, 1835) e Phyllocaulis tuberculosus (Martens, 1868) (Veronicellidae) (AgudoPadrón, 2008: 153, 162), outrora abundantes, comuns e representativas na região, rapidamente estão desaparecendo, tor- nando-se cada vez mais raro, por não dizer difícil, o seu encontro na Natureza.

A esses fatores previamente comentados vêm se somando o paralelamente crescente e alarmante avanço espacial e ocupação de nichos tróficos por parte de moluscos exóticos invasores e/ou introduzidos (Agudo-Padrón e Lenhard, 2010), especificamente - no caso que nesta oportunidade nos ocupa - de lesmas exóticas.

A partir de ocorrência registrada no mês de novembro 2011 (Agudo-Padrón, 2012) vem sendo verificada e confirmada, em terrenos de fazenda particular localizada no Município Catarinense de Monte Carlo, a ocorrência e ocupação espacial extremamente abundante de lesmas exóticas invasoras européias pertencentes às espécies Ambigolimax valentianus (Férussac, 1822) e Limax maximus (Linnaeus, 1758) (Figura 2), representantes da Família Limacidae (Agudo-Padrón, 2012). 


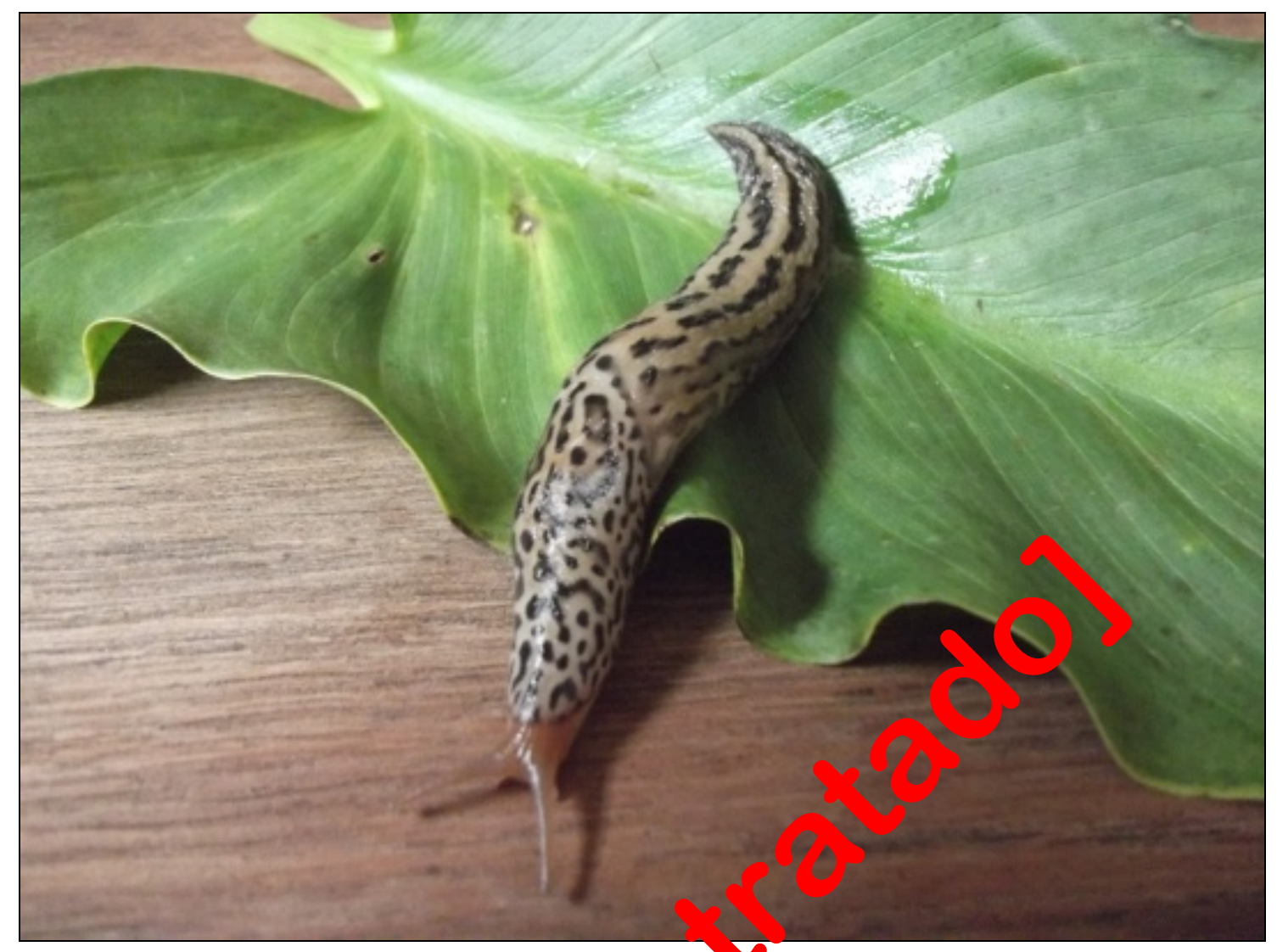

Figura 2. Lesma exótica europeia Limax maximus 4 $70 \mathrm{~mm}$ de comprimento.

Material testemunho de ap as espécies, procedente da localidade $\mathrm{fe}$ da, encontra-se hoje depositado na Coleção Malacológica, do Museu de é cia e Tecnologia da Pontif ?niversidade Católica do Rio Grand do fal (MCP), no Município d Pu to Alegre-RS, configurando ma $7 \mathrm{Ar}$ acréscimo para o registro ge ráf o destes moluscos continentais oc rentes no território do Estado de Santa Catarina (Agudo e Bleicker, 2006; Agudo-Padrón, 2008a: 158, 170; Agudo-Padrón, 2008b; Agudo-Padrón, 2011) e Região Sul do Brasil em geral (Agudo-Padrón, 2009a, b).

Além das anteriormente citadas, outras formas gastrópodes exóticas que ainda ocorrem na região, igualmente ocupando rapidamente os nichos tróficos vazios deixados pelas desaparecidas espécies nativas antes comentadas (AgudoPadrón, 2008a, 2011; Gomes et al., 2011) são a pequena lesma norteamericana Deroceras laeve (Müller, 1774) (Agriolimacidae), a lesma chinesa Meghimatium pictum (Stoliczka, 1873) (Philomycidae), particularmente referida em Agudo-Padrón (2011:54, Figuras 3, 56) sob a sinonímia Pallifera sp. o pequeno e popular caracol asiático de jardim Bradybaena similaris (Férussac, 1821) (Bradybaenidae Pilsbry, 1934), a lesma européia Limacus flavus (Linnaeus, 1758) (Limacidae Gray, 1824) e, finalmente, o famoso "escargot" europeu Helix (Cornu) aspersa Müller, 1774 (Helicidae Rafinesque, 1820), este último encontrado em forma abundante nos espaços antropizados/ urbanizados dos vizinhos Municípios Serranos de Fraiburgo e Lages.

\section{Declaração de conflito de interesses}

Os autores declaram não haver conflitos de interesses. 


\section{Referências}

Agudo-Padrón, A. I. Listagem sistemática dos moluscos continentais ocorrentes no Estado de Santa Catarina, Brasil. Comunicaciones de la Sociedad Malacológica del Uruguay, v. 9, n. 91, p. 147-179, 2008a. Disponível em: $<$ http://www.redalyc.org/articulo.oa?id=524120 49003>. Acesso em: 05 dez. 2015.

Agudo-Padrón, A. I. Ocorrência confirmada da semi-lesma exótica européia Milax valentianus Férussac, 1821 na Região Sul do Brasil. Informativo SBMa, v. 39, n. 166, p. 3, 2008 b. Disponível em: <http://sbmalacologia.com.br/ wp-content/uploads/2012/01/Info-39-166.pdf>. Acesso em: 05 dez. 2015.

Agudo-Padrón, A. I. Malacofauna "urbana” do Bairro Vila Regina, Cachoeirinha, Região Metropolitana de Porto Alegre, RS, Brasil, com especial ênfase no Helix (Cornu) aspersa Müller, 1774. II. Novos registros. Informativo SBMa, v. 40, n. 168, p. 3-5, 2009a. Disponível em: <http://sbmalacologia.com.br/wp-content/ uploads/2012/01/Info-40-168.pdf>. Acesso em: 05 dez. 2015.

Agudo-Padrón, A. I. First confirmed record of the exotic slug Milax gagates (Draparnaud, 1801) in the Southernmost Brazil Region.
Agudo-Padrón, A. I. Conservation of endemic land snails in Southern Brasil: new records of alien European slugs in the Highlands of Santa Catarina State. Tentacle, v. 20, p. 24-25, 2012. Disponível em: <http://www.hawaii.edu/ cowielab/tentacle/Tentacle_20.pdf $>$. Acesso em: 05 dez. 2015.

Agudo-Padrón, A. I.; Bleicker, M. S. Moluscos exóticos no Estado de Santa Catarina. Informativo SBMa, v. 37, n. 157, p. 6-8, 2006. Disponível em: <http://sbmalacologia.com.br/ wp-content/uploads/2011/11/Informativo-37157-30-09-2006.pdf> . Acesso em: 05 dez. 2015. Agudo-Padrón, A. I.; Lenhard, P. Introduced and invasive exotic molluscs in Brazil: an brief overview. Tentacle, v. 1, p. 37-41, 2010. Disponível em: <httn:// $\mathrm{h}$ w.hawaii.edu/ cowielab/tentacle/Tentac to pdt Acesso em: 05 dez. 2015.

Gomes, S. R.; Pican Q, J 3.; Colley, E.; AgudoPadrón, A. I.; Nàro, E.; Thomé, J. W. A newly in oduef 1 and invasive land slug in Brazil: Nre himutium pictum (Gastropoda, Philom c e) Irom China. Proceedings of the Aca em 0 Natural Sciences of Philadelphia, v 1, n. 1, p. 87-95, 2011. Disponível em: ttp. smtpilimitado.com/kennel/lesmachinesa nobrasil.pdf>. Acesso em: 05 dez. 2015.

Ellipsaria, v. 11, n. 3, p. 15-16, 2009 Disponível em: <http://molluskconserva org/EVENTS/ELLIPSARIA/Ellipsaria2009_1 3.pdf $>$. Acesso em: 05 dez. 2015.

Agudo-Padrón, A. I. Exotic mollusss $S$ nta Catarina's State, Southern B az Region (Mollusca, Gastropoda et Broalv . I ck list and regional spatial dis uth wledge. Biodiversity Journal, v. n. n. 53-58, 2011. Disponível em: $<$ http://www.biodi Pro iotrnal.com/pdf/2_5358.pdf>. Aces o em 's dez. 2015.

Informação da Licença: Este é um artigo Open Access distribuído sob os termos da Licença Creative Commons Attribution, que permite uso irrestrito, distribuição e reprodução em qualquer meio, desde que a obra original seja devidamente citada. 